\title{
Eckler, Rebecca. (2019). Blissfully Blended Bullshit: The Uncomfortable Truth of Blending Families. Toronto: Dundurn Press.
}

\author{
Reviewed by: Natasha Biglete, MacEwan University
}

Rebecca Eckler's book, "Blissfully Blended Bullshit," is a humorous and emotionally draining autobiography that takes us through her own experience of blended families along with heart-wrenching realities of relationship fallouts when in blended families. Eckler is a Canadian journalist and author whose work has appeared in the "New York Times" and "Globe and Mail" and is an executive editor of a parenting website called "SavvyMom". In her memoir, Eckler describes the highs and lows of having new roles, new family traditions, and new lifestyles colliding against one another in a modern family blended household.

Her experiences with her Ex-Boyfriend started as a blissful dream of having a rebound onenight stand to believing that she had found the One and acquiring two new bonus children and one that she shares with her Ex-Boyfriend. Still, as years went by, the dream she romanticized became a nightmare of constant mental and physical exhaustion through sorting out family, values, and belief differences from the perspective of two different individuals. She writes on dating and romantic relationships, family life, mental health, and break-up experiences in a blended family, spilling these feelings and moments on the table for us to experience with her. The title alone, "Blissfully Blended Bullshit," indicates how personal and honest this memoir is to the author. There are uses of graphic words throughout the book, emphasizing that this was a real, genuine, 
and complicated mental and physical experience.

After her divorce, Eckler searches for an escape - a rebound relationship or one-night stand - to help her forget about the emotional pain. This one-night stand relationship was supposed to be nothing more than it was already - a one-night stand, a rebound relationship of a single mother and a stranger. Meeting her (now) Ex-Boyfriend, who she referred to as One-Night Stand during this time, was a moment of forgotten responsibilities and "mind-boggling action" (p. 16). This rebound relationship does not last as there is a further development of feelings. As most relationships start, their dating life falls into a honeymoon phase where they are head over heels in love and in love with the idea of having found their soulmate. During their period of dating, the next step in their relationship took off. Her Ex-Boyfriend had moved in with Eckler and her daughter, along with his two children part-time; this was the starting point of her blissfully blended family life. As with all couples, fights are inevitable, but for Eckler and her Ex-Boyfriend, these fights have not stopped within the seven years they have blended. These fights ranged from emotional feelings like underappreciation to financial and household contributions. Many couples share common issues, may they be within blended family couples or nuclear family couples. The constant mental labor of accounting for new traditions, roles, and lifestyles can be overwhelming in traditional families but even more so in blended families, as they have already pre-established certain norms in their family. These types of complications can put a strain on a relationship and thus affects how the partnership matures.

For the first few years into their blended family life, their family relationships were blissfully filled with love and were even more so with the new addition of Baby Holt into their lives. Still, no family can be perfect and peaceful all the time, and as Eckler says that "it actually 
took a surprisingly decent amount of time for the first bump to plant itself right in the middle of our love highway" (p. 63). The birth of her son "was a breeze" (p. 63) compared to the conflicts such as the Hi/Bye, family/spousal contributions, differences in attitude towards each other's children, etc. All families, as Eckler writes, have problems. Still, many of the issues she has lived through have been different from a traditional nuclear family where all children are biologically related. Simple questions such as "How many children do you have?" are expressed by Eckler to “...making you feel fucking clueless, incapable of answering what is, really, a fucking simple question..." (p. 123) when in a blended family. She feels that no answer she gives makes her “...feel completely at ease” (p. 122).

She and many in blended families felt this experience; one of her friends who also grew up in a blended family tells her experience of having a stepfather and difficulty answering such questions. Being in a blended family, her friend did not call her stepfather 'Dad' as he was not their dad and so was called by his name instead, so even simple things such as gifts for Father's Day were difficult. It is not just the parents in the blended family that have difficulties answering such simple questions but children, too, have problems with such questions.

Various issues, whether in blended families or nuclear families, are complicated and confusing in many households. The well-being and constant mental labor of accounting for new traditions, roles, and lifestyles can be overwhelming in traditional families. Still, they can be even more so in blended families as they have already pre-established certain norms in their family. Eckler mentions that her Ex-Boyfriend did not give her the comfort and empathy she needed when she felt depressed, tired, and isolated from the family. The mental exhaustion that can come accommodating for certain family members and having to bite your tongue to avoid fights can 
indeed cause a build-up of mental and physical fatigue. Eckler compares her physical state to that of a "...turtle who has smoked a joint or...running with bricks on my feet, not going anywhere" (p. 222). As mentioned before, arguments and fights are unavoidable when in a relationship, even more so for those living together, but consistent arguments take a toll on a person's mental and physical state. For Eckler, she felt trapped in many instances of depression and escapism from her blended life. However, it was a terrible moment to be in; realizing that this mentality was due to the fallout of her relationship and blended life allowed Eckler to take herself away from what seemed like a very toxic relationship.

Near the end of the memoir, Eckler tells us that she doesn't remember the day she fell in love but instead remembers clearly the day she fell out of love. The day that she fell out of love, on October thirtieth, was nothing short of an emotional loss of respect and appreciation for her ExBoyfriend. Eckler writes, "the fact that Boyfriend has gone to a party, knowing where I am and that something is wrong with my daughter, breaks my heart. Falling in love is a process. Falling out of love can also be a process. But like those who profess they fell in love at first sight, I know I've fallen out of love in an instant"' (p. 240).

This incident becomes the breaking point for Eckler. No longer loving him "or, for that matter, like him" (p. 240) and that "October thirtieth is the night I clock out of my blended family. I'm simply done with the bullshit. It's not blissful anymore. It will never be blissful again” (p. 240). Although this was a breaking point for Eckler, the relationship and blending were dragged on for another two years in hopes of everything possibly working out in the end. Her decision to keep the relationship going was because of her son, Holt, and concerns as a role model for Rowan, her daughter. But it turned out that they were too different and weren't meant for each other. Be- 
coming a serial divorcee and going through yet another breakup was never an easy process, but at some point, the family had seemed to stop trying. Thus, it was better for everyone if they ended up going their separate ways.

Eckler's memoir on her experience gives an insider view of how blended families look behind closed doors. She lays out the struggles that go on when trying to maintain the partnership and family relations. More often than not, many of the events she tells us are more relevant in terms of romantic relationship downfalls than blended families. But, blending their families and the complications attached did indeed put stress on their relationship. The memoir felt more like a single mother's look at parent dating and the emotional angst that comes with it, thus blending without thinking of possible repercussions. Disciplines such as family sociology, social work, counseling, and family and child psychology may benefit from this memoir. Eckler's way of presenting her past choices makes you stunned and see the sheer graphic honesty she portrays in her blending experience. I found this book interesting, emotional, eye-opening, entertaining, confusing to follow, and a painful read. I recommend this book for anyone who may relate to or who has gone through bad relationships or complicated family issues. 